\title{
Determining the Spatial Pattern of Blackleg Diseased Potato Plants in the Field and Simulated Post-Harvest Tuber Infections in Potato Crates
}

\author{
Thomas H. Been $^{1} \mathbb{D}$. Johanna E. Beniers ${ }^{1} \cdot \operatorname{Jan}$ M. van der Wolf ${ }^{1} \mathbb{C}$
}

Received: 6 April 2021 / Accepted: 17 September 2021 / Published online: 29 October 2021

(c) The Author(s) 2021

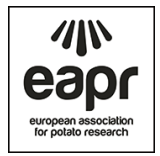

\begin{abstract}
Experiments were carried out in 2012 and 2013 to answer two basic questions in the testing of potato blackleg causing agents before and after harvest. Firstly, what is the spatial distribution of symptomatic plants in the field. Secondly, what is the distribution of infected tubers over the crates and the resulting detection probability using the standard method of collecting 200 tubers from the top crates in storage. In both years, ten farmers were equipped with a global positioning system (Garmin GPSMAP 62) and asked to register the position of blackleg diseased plants every time they scouted their potato lot for diseases. To answer the second question, potatoes marked with four nails (only visible internally after harvest) and potatoes with a different skin colour were added to one-hectare (ha) fields of seed potatoes in different patterns of aggregation ranging from random, to aggregated distribution, up to one big hotspot prior to harvest. The invisibly marked tubers were used for the unbiased collection of twenty 200tuber samples from the storage crates, while the coloured skin tubers were used to ascertain, when the potatoes were graded, the distribution of 'infected' potatoes over the storage crates. The experiment was carried out with 0.05 and $0.1 \%$ disease incidence, in 2012 and 2013, respectively. Twenty two out of 26 fields proved to have a random pattern of diseased plants at harvest, which indicates that the blackleg diseased plants came into the field as infected seed potatoes. Two of the four aggregated patterns detected, started out as random distributions but became aggregated later in time, indicating spread in the field. A random spatial pattern in the field at harvest proved to result in a uniform distribution of infected tubers in the crates and, consequently, sampling of only the top crates for the 200-tuber sample does not introduce any bias. Fifty percent of the infected farmer lots were detected by the Nederlandse Algemene Keuringsdienst inspectors performing their official field surveys, which was a better performance than the $18 \%$ detection obtained by the standard 200-tuber sampling method. Only 6 out of 80 samples from the 'infected' lots with $0.05 \%$ disease incidence level, and 22 out of 80 samples at the $0.1 \%$ disease incidence level were detected by the latter method. It was concluded that intensifying the field survey would be cheaper and more successful than enlarging the tuber sample size to increase the probability for detection of infected seed lots.
\end{abstract}

Keywords Blackleg detection - Dickeya $\cdot$ Pectobacterium $\cdot$ Spatial distribution of diseased plants $\cdot$ Surveys $\cdot$ Tuber sampling

Extended author information available on the last page of the article 


\section{Introduction}

Dickeya and Pectobacterium species, belonging to the family of soft rot Pectobacteriaceae (SRP), cause blackleg of potatoes, an economically important disease that is mainly tuber-borne. In Europe, two Dickeya species, i.e. D. solani and D. dianthicola, and three Pectobacterium species, i.e. P. atrosepticum, $P$. parmentieri and P. brasiliense, are largely responsible for blackleg (Van der Wolf et al. 2021a). There are no potato cultivars available which are resistant to SRP, and no control agents are registered for treatment of plant material. Disease management in the European Union is predominantly based on the obligatory use of seed potatoes in which the disease is absent or only present in a low incidence (Van der Wolf et al. 2021b). Currently, seed testing and certification is solely based on field inspections.

While the crop is growing, inspectors of national inspection services will scout the field for diseased plants two to three times during the growing season. A visual inspection is performed while the inspector is traversing the plot in a certain pattern. An inspector can spot diseased plants at a 5-m distance to both sides of their inspection path. In the Netherlands, it is common practice that, if no prior knowledge is available, a $\mathrm{Z}$ pattern is used, but if historical information is available, the inspection will focus on sites with expected higher risks for diseased plants. At most, 5 to $10 \%$ of the surface area is visually inspected. The larger the area of the lot, the smaller the percentage of the lot which is inspected. When the incidence of visual infections is low, symptomatic plants are readily missed. The absence of a relation between plot size and inspected area poses a legal problem as smaller plots have a higher probability of detection and consequently downgrading or rejection of produce, compared to larger plots.

In the Netherlands, in the period between 2015 and 2019, in addition to the field inspections, a post-harvest tuber testing was conducted on all pre-basic seed lots. The results were not used for certification, but used by growers and the inspection service to improve disease management. After the tubers had been stored, 200 tubers were collected randomly from the crates from the top of the stacks. Subsequently, the peel of the heel ends of the collected tubers were sampled and analysed by an enrichment multiplex (Bioplex) TaqMan assay (De Haan and Van Den Bovenkamp 2009; Van der Wolf et al. 2021c). The number of crates sampled depends on the area of the plot. However, only the top crates are sampled, as random or stratified sampling of all crates from one lot is a logistic impossibility. The sampling of the top crates is only valid for collecting a representative sample if a random distribution of infected tubers in the field and hence in the crates applies. Assuming this to be true we can directly calculate the detection probabilities - the collection of at least one infected tuber in a sample — based on the infection incidence of the seed lot and the numbers of tubers tested.

In Fig. 1, this relationship is graphically presented for an infection incidence of $0.05 \%$ of the tubers. It shows that analysis of 200 tubers only provides a 
probability of $9.5 \%$ or less that an infected tuber will be present in the sample. It further indicates that more than 4600 out of 40,000 tubers/ha must be tested to obtain a probability of $90 \%$ that an infected tuber is present in this large sample. With the current 200-tuber sampling method, 1 out of 87 tubers in the field must be infected to obtain a $90 \%$ probability that at least one infected tuber gets into the sample that is processed. Any laboratory error still must be added and will reduce the probability of detection.

Methods and procedures to detect SRP in the lab have been improved tremendously in recent years. In general, molecular detection techniques are applied, often in combination with an enrichment procedure (Czajkowski et al. 2015; Van der Wolf et al. 2021c). The methods are highly reliable, sensitive, and the risks for false-positive or negative results are considered low. The detection probability therefore is largely dependent on the infection incidence and the distribution of infected tubers in crates post-harvest. This in turn will be dependent on the spatial distribution of infected tubers in the field and the redistribution during the harvesting process.

Likely, the distribution of infected progeny tubers in the field is related to the distribution of blackleg-diseased plants, although infected tubers will also be harvested from symptomless infected plants. Knowledge concerning the spatial distribution of SRP-infected plants in the field, whether symptomatic or latent, is almost absent as well as the knowledge concerning the distribution of diseased tubers over the crates in storage and the probably biased sampling of the top crates.

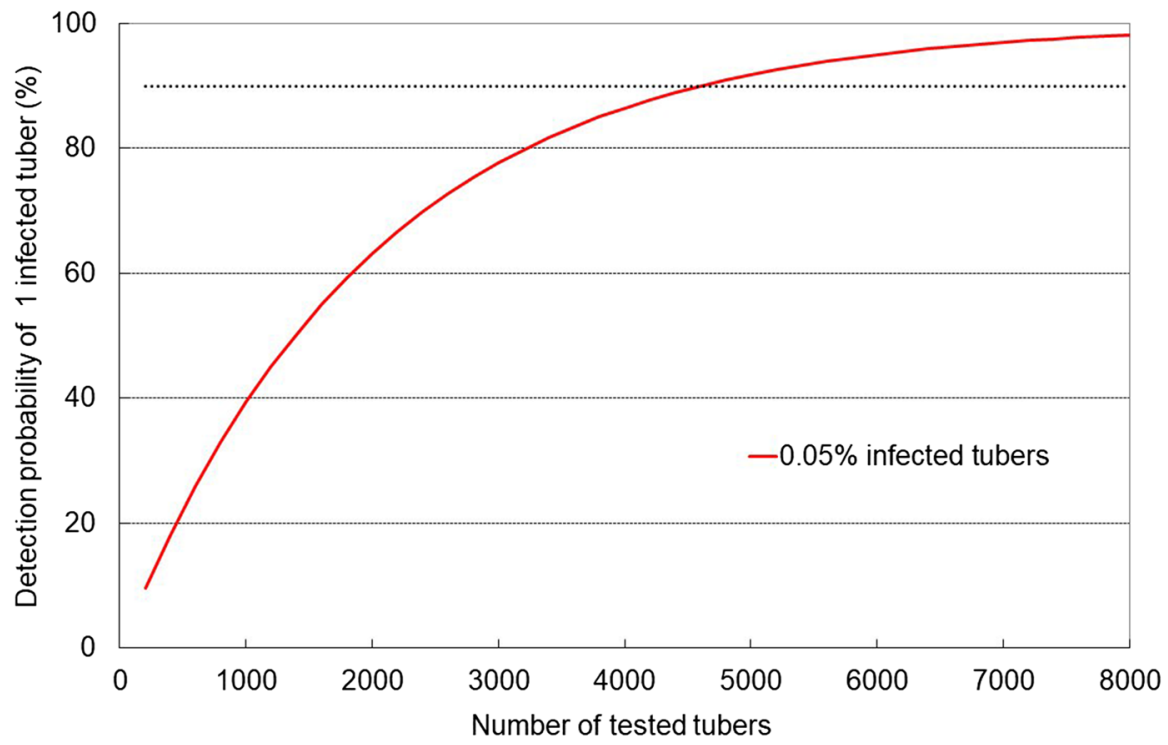

Fig. 1 Number of tested tubers and the probability of detection according to a Poisson distribution based on a $0.05 \%$ of infected tubers in the lot 
There are three possibilities to improve detection of tuber infections:

1. An improved scouting protocol covering a larger area of the crop. When the disease incidence is small (few plants with visible symptoms), and a random distribution in the field is presumed, the detection of infected lots could increase proportionally with the increased area inspected. The more aggregated the infestation of Dickeya solani, the smaller the gain in detection, as in an aggregated distribution the incidence of finding another diseased plant decreases with increasing distance of the first find.

2. Increasing the number of tubers analysed after harvest, as illustrated in Fig. 1. An upgrade to 400 tubers tested will almost double the detection probability from 9.52 to $18.13 \%$ at the $0.05 \%$ incidence level.

3. Improving the detection procedure in the lab used to screen the 200 potatoes. Obviously, this will not help the detection of infections which already have been missed when the 200-tuber sample was collected. However, the analysis of sample extracts taken from the entire tuber peel instead of the heel end may be of added value. Increasing the sensitivity of the assay is expected to have only a small impact.

Currently, there are two basic questions which are still not adequately answered and which will affect any measure taken to prevent an infested lot to enter the production chain. The first concerns the nature of the spatial distribution of blackleg diseased plants in the field. Is this a random distribution as often is assumed or is this a more clustered distribution? Randomness mostly indicates that the infestations arrived from outside the field, e.g. an infected seed tuber lot, while an aggregated distribution points towards redistribution processes within the field. The second question is connected to the collection of the 200-tuber sample. What is the real distribution of infected and contaminated tubers over the crates? Is this distribution independent from the spatial distribution in the field?

Studies on the distribution of marked tubers in crates harvested from fields with different levels of aggregations have been performed previously (Janse and Wenneker 2002). However, the lay-out of the experiment was inadequately described and the used methodology with visible, easily recognizable marked potatoes questionable. Therefore, the question remains what the real spatial distribution of symptomatic plants in the field and infected tubers post-harvest might be. The success of tuber sampling decreases when the field distribution is a more aggregated one. In order to explore new strategies, it is necessary to obtain more insights regarding the spatial distribution of blackleg diseased plants in the field.

In this paper, the distribution of blackleg diseased plants in naturally infected seed potato crops was studied to gain insight in the level of aggregation of infected tubers. In addition, the effect of different degrees of clustering in the field of, invisibly marked, tubers on their distribution over the storage crates was investigated to determine the detection probability by standard tuber testing. 


\section{Materials and Methods}

\section{Spatial Distribution of Symptomatic Plants in the Field}

In 2012 and 2013, ten seed potato growers, who generally go through their fields to weed out diseased plants, were asked to log these plants using a handheld global positioning system (GPS) (Garmin GPSMAP 62). The GPS of this model, supported by WAAS and Hotfix, has a precision of approximately $3 \mathrm{~m}$ when acquiring the position. Both position (waypoint) and date of detection of each Dickeya solani diseased plant were registered. The device can operate for $16 \mathrm{~h}$ on a full battery load and can $\log$ up to 2000 GPS-Waypoints without any further action of the farmer. After scoring, the diseased plants were removed, although the rotten mother tubers mostly stayed behind. After harvest, the collected waypoints of each device were downloaded and visualized using the smart farming platform akkerweb.eu (Van Evert et al. 2018). Each farmer also provided the relevant field specific data including field size, cultivar grown, quality of the potato cultivar, planting date, and the final review of the official inspector. In Table 1, an overview is presented of the fields and data collected.

The data of the spatial distribution of symptomatic plants in the field were analysed for complete spatial randomness (CSR) assuming that symptomatic plants follow a homogeneous Poisson process over the study area. Several methods are available to test for CSR. The Quadrat test (Ott and Longnecker 2015), the nearest neighbour distance method and the K-function test (Ripley 1976) are the most commonly used. The quadrat test suffers from several drawbacks: (1) the effect of chosen sub-region size on the result, (2) it's more a measure of dispersion than pattern encountered as it is based primarily on the density of points, and not their arrangement in relation to one another, and (3) it results in a single measure for the entire distribution, so variation of spatial patterns within the region are not recognized. The nearest neighbour test considers only the shortest scales of variation. Therefore, we chose to use the second order K-function to test for CSR. It provides an estimate of spatial dependence over a wider range of scales and is based on all the distances between points in the study area. Data were analysed using scripts written in the Tinn-R editor version 4.00.03.5 and run in $\mathrm{R}$ version 3.6.1 using the SpatStat package V1.63-3 'Wet paint' (Baddeley and Turner 2005; Baddeley et al. 2015).

Data per field were pooled over all observations dates available, presenting the spatial pattern of diseased plants at the end of the growing season. Only fields with $>25$ GPS-Waypoints can be analysed for CSR. To analyse the GPS-Waypoints using the SpatStat package, the latitude/longitude-coordinates of the Garmin GPSMAP 62 had to be transformed into X, Y coordinates and, if needed, projected to fit into a horizontal outlined rectangular grid. For the latter, the $\mathrm{X}$-coordinates were transformed using the formula

$$
\mathrm{X}_{\text {new }}=\operatorname{sqrt}\left((\mathrm{Y} 2-\mathrm{Y} 1)^{2}+(\mathrm{X} 2-\mathrm{X} 1)^{2}\right)
$$

with $\mathrm{X} 1$ and $\mathrm{Y} 1$ the coordinates of the intercept of the fitted linear regression through the data points. The new Y-coordinates were calculated as the 


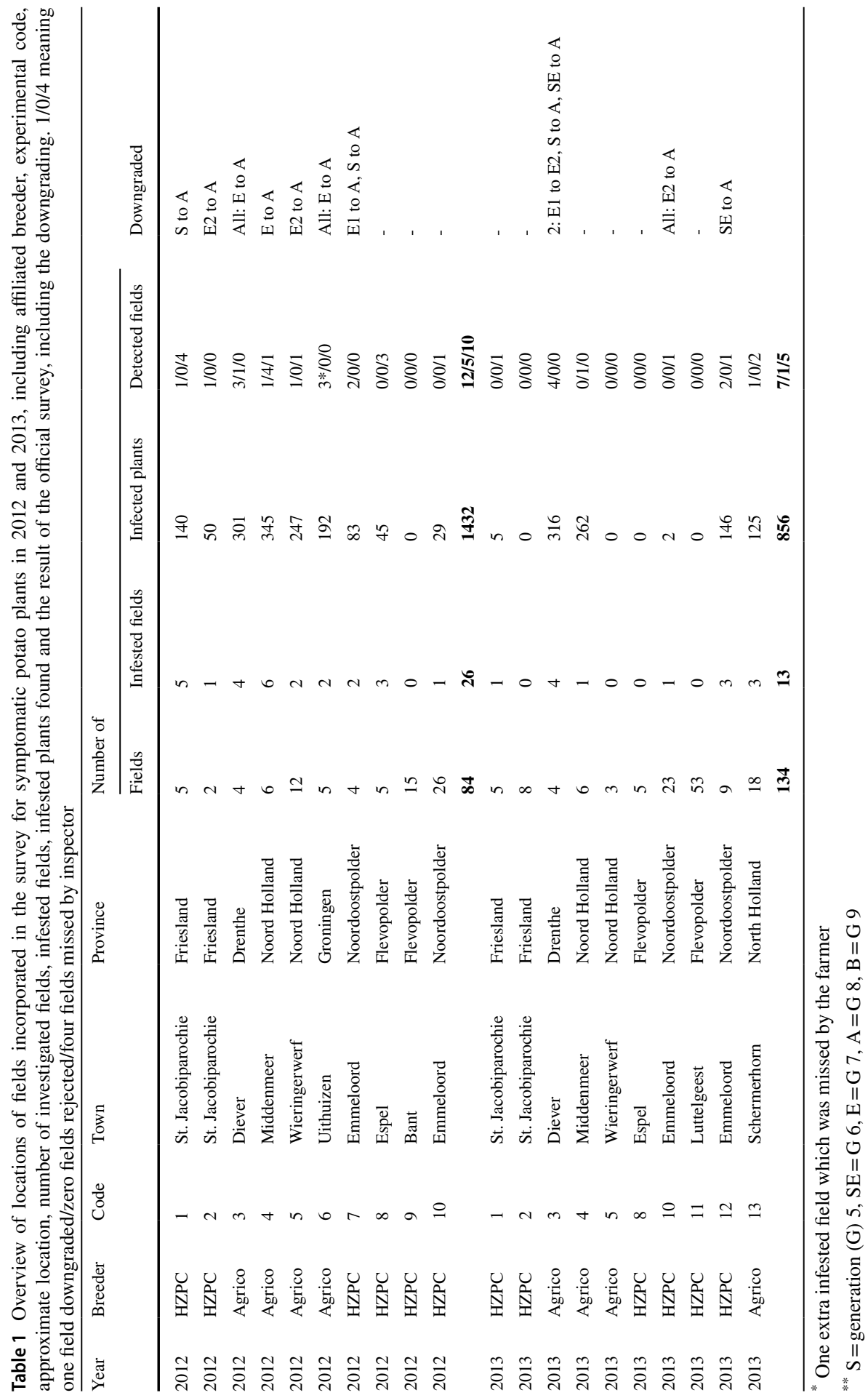


deviation between the $\mathrm{Y}$ value of the datapoint and the fitted $\mathrm{Y}$ value according to the regression.

$$
\text { Ynew }=\mathrm{Y}-(\mathrm{aX}+\mathrm{b})
$$

The standardized K-function, also called the L-function, was used for the Monte Carlo simulations to test for CSR, whereby interpreting $\mathrm{K}$ with hypotheses $\mathrm{L}$ : $\mathrm{L}(\mathrm{h})=0$ if point process is random, $\mathrm{L}(\mathrm{h})=$ peaks of positive values if point process is clustering and $\mathrm{L}(\mathrm{h})=$ troughs of negative values if point process is regularity (uniform). The results are presented in Tables 2 and 3.

\section{Artificial Distributions of 'Infected' Plants}

Each year a seed potato lot of circa 4 hectares was selected and dived into 4 fields of approximately 1 ha. The fields were situated in the province of Flevoland, the Netherlands. In 2012 the potato cultivar Crisps4all was planted at the end of April. On field A, B and C, plant distance was $19 \mathrm{~cm}$ with a tuber size of $55^{+} \mathrm{mm}$, while on field $\mathrm{D}$, using a tuber size of $35 / 55 \mathrm{~mm}$, plant distance was set to $16 \mathrm{~cm}$. Between rows, distance was $75 \mathrm{~cm}$, with a total length of $284 \mathrm{~m}$ per row. The expected yield, based on the farmer's experience, was assumed to be 10 tubers per plant in field $\mathrm{A}, \mathrm{B}$ and $\mathrm{C}$ and 8 tubers per plant in field $\mathrm{D}$, and the required number of 'infected' tubers was calculated. In 2013 cultivar Desiree was planted at the end of April. The potato lot was about 5.4 ha and was divided into 4 fields of approximately 1.35 ha. Plant distance in the row was $14 \mathrm{~cm}$; between rows, distance was $75 \mathrm{~cm}$ and tuber size $35 / 55 \mathrm{~mm}$. The length of the fields was $283 \mathrm{~m}$, each containing 64 rows. A yield of seven tubers per plant, again based on farmer's experience, was assumed for the calculation of the expected number of tubers. In Table 4, an overview of the field characteristics of both years of this research is presented.

\section{Adding Invisibly Marked and Coloured Skin 'Infected' Tubers}

Prior to harvest, two kinds of 'infected tubers' were added in such a way that four different spatial distribution patterns were created, ranging from a full random distribution, to clustered distributions up to a single large hotspot (Fig. 2). Both invisibly marked tubers and tubers with a different skin colour were added using the same pattern. The first was to enable the collection of random 200-tuber samples from crates in storage to check for the presence of 'infected' tubers in these samples, the latter to easily quantify the dispersion of tubers from the different distribution patterns over the stored crates, when the potatoes were sorted for shipment. The incidence of 'infected tubers' was set to $0.05 \%$ in 2012 and $0.10 \%$ in 2013 .

After haulm killing in early August (2012) and early September (2013), tubers were excavated on each randomly acquired position in the field and invisibly marked by pressing one front end of the tuber into a set of four nails mounted to a board, after which the tubers were replaced at the same depth of the tilth. When harvested, these markings were invisible to the eye. At the same time, an identical number of tubers of cultivar Bildtstar (2012) and Berber (2013), same shape and size, were 
Table 2 Result of CSR analysis regarding the spatial distribution pattern of symptomatic plants in the field in 2012 and 2013. Experimental code, seed potato lot number, length and width of lot, number of diseased plants per survey, total number of diseased plants and the spatial distribution at harvest. Lots with less than 25 data points could not be analysed

\begin{tabular}{|c|c|c|c|c|c|c|c|}
\hline \multirow[t]{2}{*}{ Year } & \multirow[t]{2}{*}{ Farmer code } & \multirow[t]{2}{*}{ Seed potato lot } & \multirow{2}{*}{$\begin{array}{l}\text { Length } \\
\text { (m) }\end{array}$} & \multirow{2}{*}{$\begin{array}{l}\text { Width } \\
\text { (m) }\end{array}$} & \multicolumn{2}{|l|}{ Number of diseased plants } & \multirow{2}{*}{$\begin{array}{l}\text { K-test } \\
\text { (Ripley) }\end{array}$} \\
\hline & & & & & at time $(\mathrm{t} 1+\mathrm{t} 2+\mathrm{t} 3 \ldots)$ & Total & \\
\hline \multirow[t]{27}{*}{2012} & 1 & 1 & 420 & 90 & 2 & 2 & - \\
\hline & 1 & 2 & 180 & 86 & $9+6$ & 15 & - \\
\hline & 1 & 3 & 200 & 113 & $16+27+49$ & 92 & Random \\
\hline & 1 & 4 & 330 & 57 & $27+2$ & 29 & Random \\
\hline & 1 & 5 & 220 & 66 & 2 & 2 & - \\
\hline & 2 & 8 & 126 & 125 & $34+12+4$ & 50 & Random \\
\hline & 3 & $4+5$ & 300 & 44 & $25+7$ & 32 & Random \\
\hline & 3 & 7 & 600 & 24 & $19+30+26$ & 75 & Random \\
\hline & 3 & 10 & 383 & 27 & $129+42+22$ & 193 & Random \\
\hline & 4 & 4 & 480 & 15 & $18+3+5+9$ & 35 & Random \\
\hline & 4 & 23 & 485 & 50 & $11+37$ & 48 & Random \\
\hline & 4 & 27 & 750 & 16 & $53+52$ & 105 & Random \\
\hline & 4 & 29 & 500 & 12 & $13+13+95$ & 121 & Random \\
\hline & 4 & 35 & 250 & 27 & 33 & 33 & Random \\
\hline & 4 & 36 & 500 & 69 & $6+1$ & 7 & - \\
\hline & 5 & 1 & 311 & 216 & $4+7+1+4$ & 16 & - \\
\hline & 5 & 2 & 400 & 160 & $15+49+61+61+32+13$ & 231 & Clustered \\
\hline & 6 & 1 & 290 & 69 & 60 & 60 & Random \\
\hline & 6 & 2 & 450 & 120 & $62+6+64$ & 132 & Clustered \\
\hline & 7 & 13 & 283 & 60 & $1+1+3$ & 5 & - \\
\hline & 7 & 16 & 283 & 102 & $1+2+1+21+53$ & 78 & Random \\
\hline & 8 & 4 & 42 & 285 & 7 & 7 & - \\
\hline & 8 & 27 & 88.5 & 285 & 4 & 4 & - \\
\hline & 8 & 29 & 12 & 285 & 1 & 1 & - \\
\hline & 8 & 31 & 108 & 285 & 31 & 31 & Random \\
\hline & 8 & 35 & 105 & 190 & 2 & 2 & - \\
\hline & 10 & $20+21$ & 172 & 250 & 29 & 29 & Random \\
\hline \multirow[t]{11}{*}{2013} & 1 & 304 & 64 & 180 & 5 & 5 & - \\
\hline & 3 & 4 & 200 & 63 & $23+21+115+114$ & 273 & Clustered \\
\hline & 3 & $16+17+18$ & 515 & 210 & $53+8$ & 61 & Random \\
\hline & 4 & 32 & 508 & 100 & 265 & 265 & Random \\
\hline & 10 & 17 & 117 & 256 & 2 & 2 & - \\
\hline & 12 & 4 & 264 & 14 & $33+1+7+5+2+2+1$ & 51 & Random \\
\hline & 12 & 8 & 183 & 50 & $12+8+25+3$ & 48 & Random \\
\hline & 12 & 9 & 183 & 50 & $12+15+8^{1}$ & 35 & Random \\
\hline & 13 & 15 & 480 & 220 & $2+24+4+13+8+6$ & 57 & Clustered \\
\hline & 13 & 12 & 550 & 145 & $7+13+6+1$ & 27 & Random \\
\hline & 13 & 17 & 580 & 300 & $2+12+2+22+6$ & 44 & Random \\
\hline
\end{tabular}

${ }^{1}$ In total 55 waypoints, 20 waypoints missing due to power loss of the GPS system 


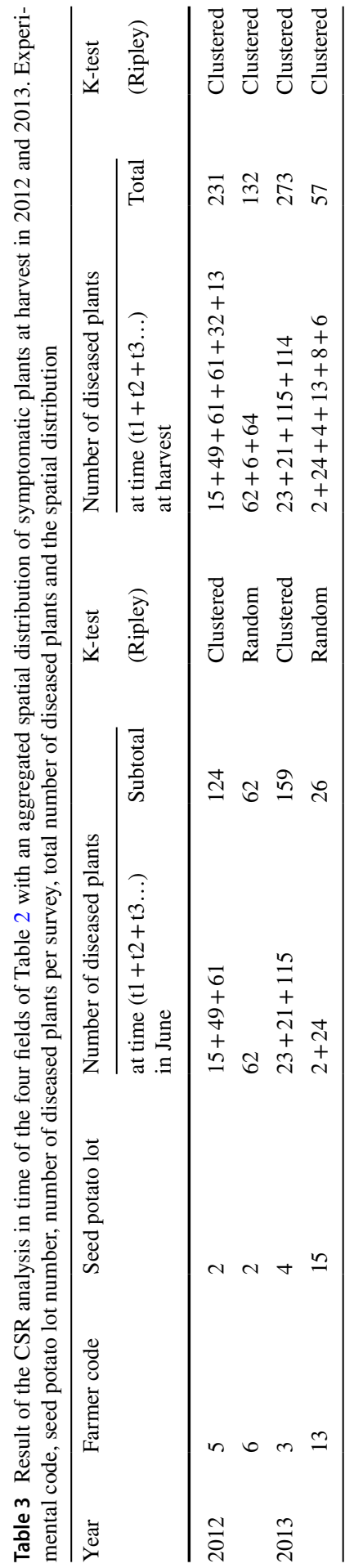




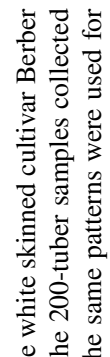

正

究家就

政

สิ

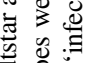

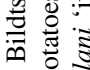

응

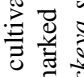

㻤

悬

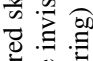

政

글

귱

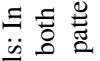

窇

믈

$\stackrel{\square}{\mathscr{2}}$

巳 :

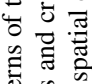

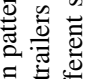

艺氖

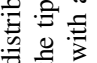

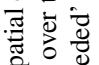

\%ํำ

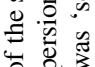

$\pi, \frac{1}{3}$

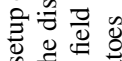

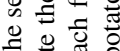

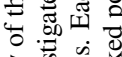

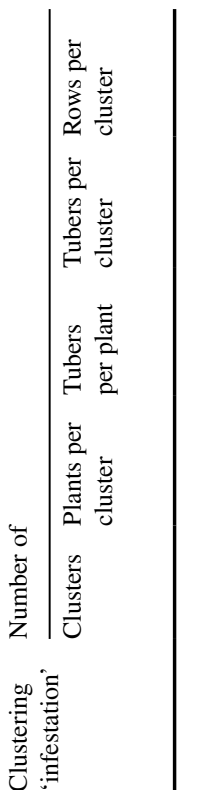

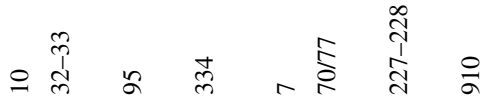

$\circ \begin{array}{lllll}a & 0 & 1 & \\ 1 & \infty & \infty\end{array}$

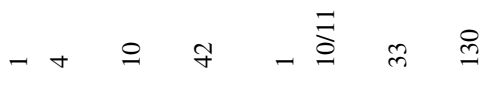

$\dot{m} \simeq+-\stackrel{0}{2}+-$

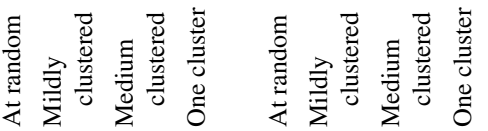

$n n$ n $\frac{n}{n} \frac{n}{n} \frac{n}{n} \frac{n}{n} \frac{n}{n}$

$920 \quad \Xi \pm \pm I$

๙

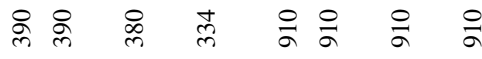

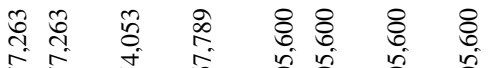

ई尺 i

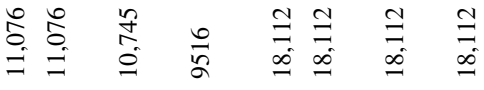

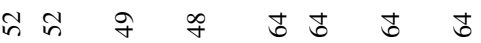

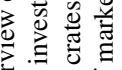

๖

$\checkmark$ 总导

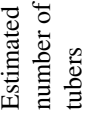

约

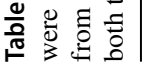

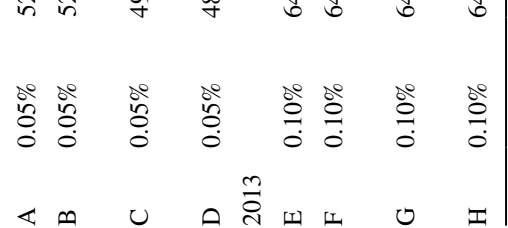




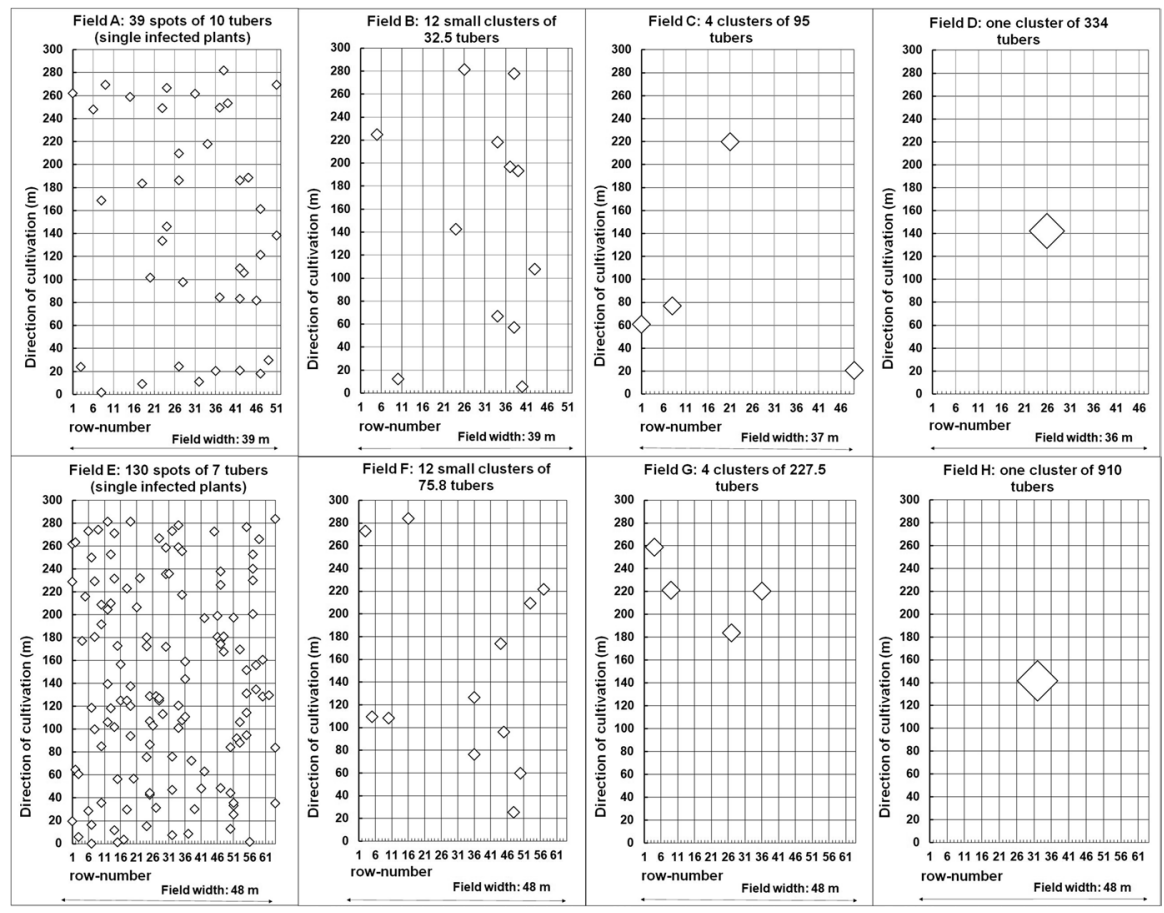

Fig. 2 Spatial distribution patterns of the 2012 and 2013 field experiments to investigate the resulting pattern of 'infected' tubers in storage. Four different distribution patterns were created. A and E fully randomized distribution, $\mathbf{B}$ and $\mathbf{F}$ small clusters, $\mathbf{C}$ and $\mathbf{G}$ large clusters and $\mathbf{D}$ and $\mathbf{H}$ single 'infection' located in the middle of the test field

added to the soil at the same location. These potato cultivars have tubers with a red and a white skin, respectively, in full contrast to the skin colour of cultivar Crisps4All in 2012 and Desiree in 2013.

The test fields in 2012 were designated A to D, and the various distribution patterns were applied on 30 August and 6 September. In field A, a completely randomized 'infestation' was created using 39 randomly chosen locations where 10 tubers were invisibly marked and 10 coloured skin tubers of cv Bildtstar were added. In test field B, 12 locations were chosen where 4 plants were harvested, and 32 or 33 tubers were invisibly marked, and red Bildtstar tubers added per location. Test field C contained 4 large spots of 10 plants situated over two rows where 95 tubers were invisibly marked, and red Bildtstar tubers were added. In test field D, one large oval-shaped infestation was situated in the middle of the field. Tubers of 42 plants covering 11 rows were marked as before: 40 plants had 8 tubers, and two plants had 7 tubers marked. In 2013 a similar approach was chosen on 16 and 18 September, but with a higher incidence of 'infected' tubers. For details, see Table 4. 


\section{Harvesting of the Tubers}

The trial fields were harvested on 20 September 2012 and 31 October 2013 with a two-row-harvester. In each field harvesting started from the middle rows and in a clockwise direction, tubers were harvested in an extending spiral; the outer rows were harvested last. When the bunker was full, the tubers were deposited in a tipper trailer. Each full tipper trailer was then emptied on a sorting belt and spread over the crates. The tipper trailer and the corresponding crates were numbered per test field in the order of entry. Then the crates were stored in stacks of 6 crates.

\section{Sampling of the Tubers}

In the autumn of each year, the stored crates were sampled according to the Nederlandse Algemene Keuringsdienst (NAK) method. Two hundred tubers $(35 / 55 \mathrm{~mm})$ were randomly collected from the top crates to obtain a standard tuber sample. This was repeated 20 times per test field (Table 5). The 16,000 collected tubers each year were assessed for the presence of the nail markings by cutting off both front ends of each tuber with a knife. If 4 necrotic spots were visible, the tuber was scored positive as 'infected').

Finally, when the stored potatoes were sorted and graded, the distribution of tubers with a different skin colour over all crates of each test field were established by 'harvesting' and counting the added, differently coloured skin tubers per crate.

\section{Results}

\section{Spatial Distribution of Symptomatic Plants in Seed Potato Lots}

In 2012, nine out of ten farmers had infected potato lots and provided data on 21 seed potato lots, while in 2013 six out of ten farmers contributed data on eight infected lots. In 2012 the disease pressure was higher than in 2013 as is reflected in the number of fields where symptomatic plants were detected compared to the total number of fields investigated. In 2012 almost $31 \%$ of the fields had blackleg infested plants, while in 2013 barely $10 \%$ of the investigated seed potato lots showed symptomatic plants. Despite this, in both years, the number of symptomatic plants in infested fields was high, except for two fields in 2013 with only 2 and 5 symptomatic plants. As only lots with more than 25 Dickeya solani diseased potato plants

Table 5 Details of the standard 200-tuber sample collection for all 8 fields

\begin{tabular}{lllll}
\hline 2012 & Field A & Field B & Field C & Field D \\
\hline Number of top crates & 5 & 5 & 6 & 4 \\
Number of tubers collected per crate & 40 & 40 & 34 & 50 \\
2013 & Field E & Field F & Field G & Field H \\
Number of top crates & 11 & 11 & 12 & 12 \\
Number of tubers collected per crate & $18 / 19$ & $18 / 19$ & $16 / 17$ & $16 / 17$ \\
\hline
\end{tabular}



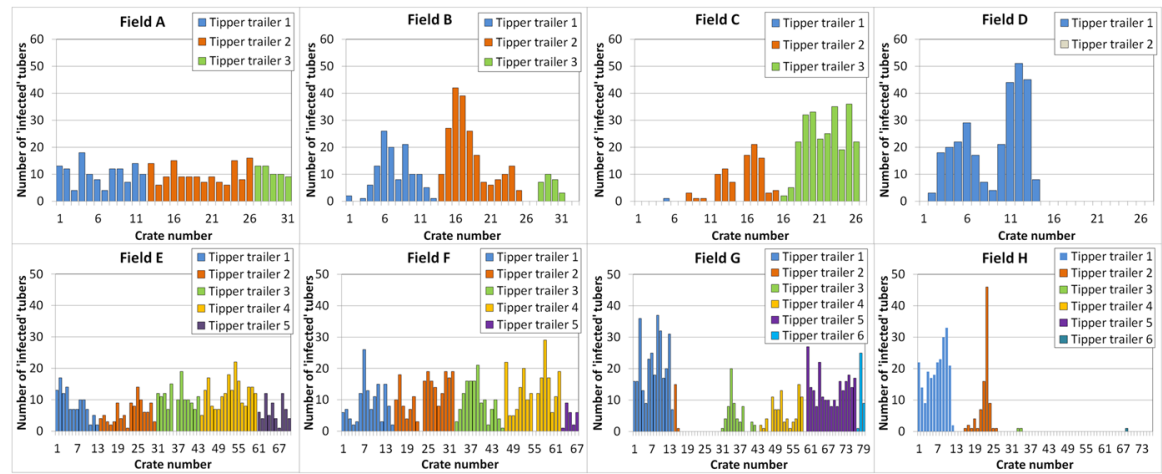

Fig. 3 Number of 'infected' red tubers of cv. Bildtstar (2012) or white tubers of cv. Berber (2013) found per crate per tipper trailer for each of the four different spatial distribution patterns: $\mathbf{A}, \mathbf{E}$ complete random distribution, B,F slightly aggregated, $\mathbf{C , G}$ heavily aggregated and $\mathbf{D}, \mathbf{H}$ one infestation focus in the middle of the field. Tipper trailer 1, the first tipper trailer with harvested tubers always started harvesting in the middle of the field

can be used for a reliable analysis, a total of 26 fields were analysed for complete spatial randomness (Table 2). Only four out of the 26 analysed fields had, according to the K-test, a clustered spatial distribution of diseased plants at harvest. The rest of the fields showed that the symptomatic plants registered had a random distribution. Reanalysing the four fields with a clustered distribution in time revealed that two of these fields started with a random distribution in June when scouting started (Table 3) and only showed aggregation later in the growing season. Table 2 also provides information on the plot size, the number of detected symptomatic plants detected per farmer survey and the total number of symptomatic plants found.

\section{Official Results}

The official results of the field inspections carried out by the NAK inspectors for NAK certification are presented in the last two columns of Table 1. Out of the 84 seed potato lots surveyed by the farmers in 2012, 26 contained plants with blackleg symptoms. Of these 26 infected fields, 16 were recognized as such by the official inspection. Five of these seed potato lots were rejected, while 11 were downgraded. Ten infestations were missed by the inspectors. One additional infestation, missed by the farmer, was detected by an inspector and the lot was downgraded. In 2013 the number of surveyed seed potato lots increased to 134 , but only 13 contained symptomatic plants during the surveys. One field was rejected, and seven fields were downgraded. Five fields were missed by the official inspection.

\section{Distribution over the Crates}

In Fig. 3 and Table 6, the number of 'infected' tubers is presented per tipper trailer and per crate. Harvesting always started in the middle row of the seed potato lot 


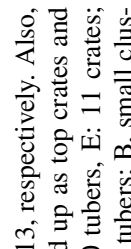

궁

릉

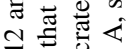

穴过

$\Xi$ 要苛

월

节主

बै

훈 $\times \frac{0}{x}$

$\Xi$ 常 $x$

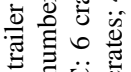

可记

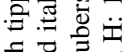

듕

형워

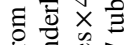

$\Leftrightarrow$ 记

过

50

¿

苍范苛

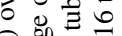

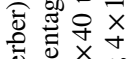

Dी

过 诃

的工

吾

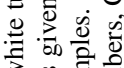

을

记

要

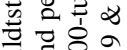

흠 छ

르뤄

苛苍苍

ญ

氖.

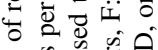

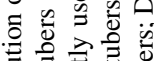

声育志

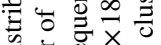

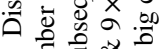

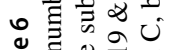

응

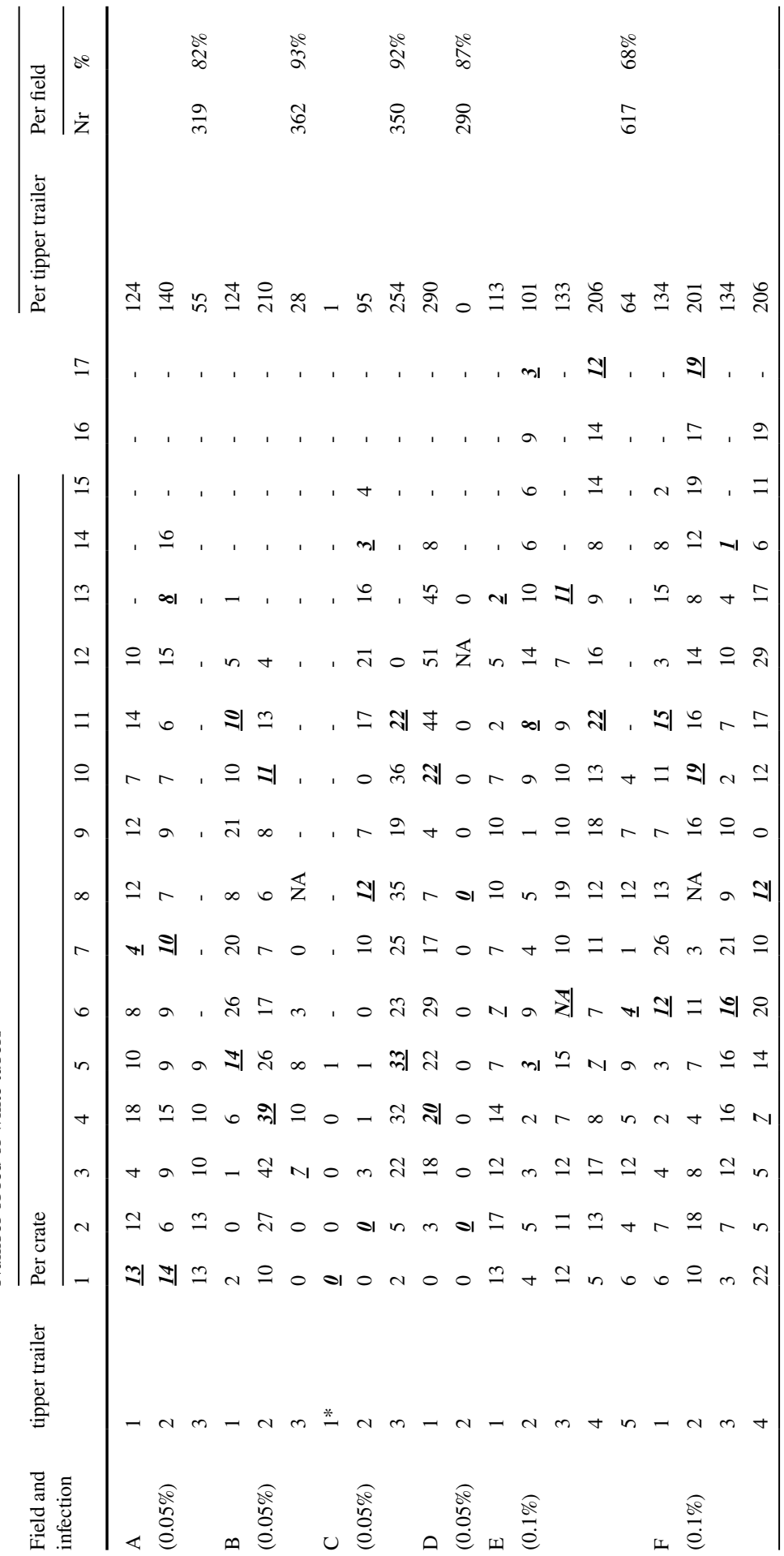




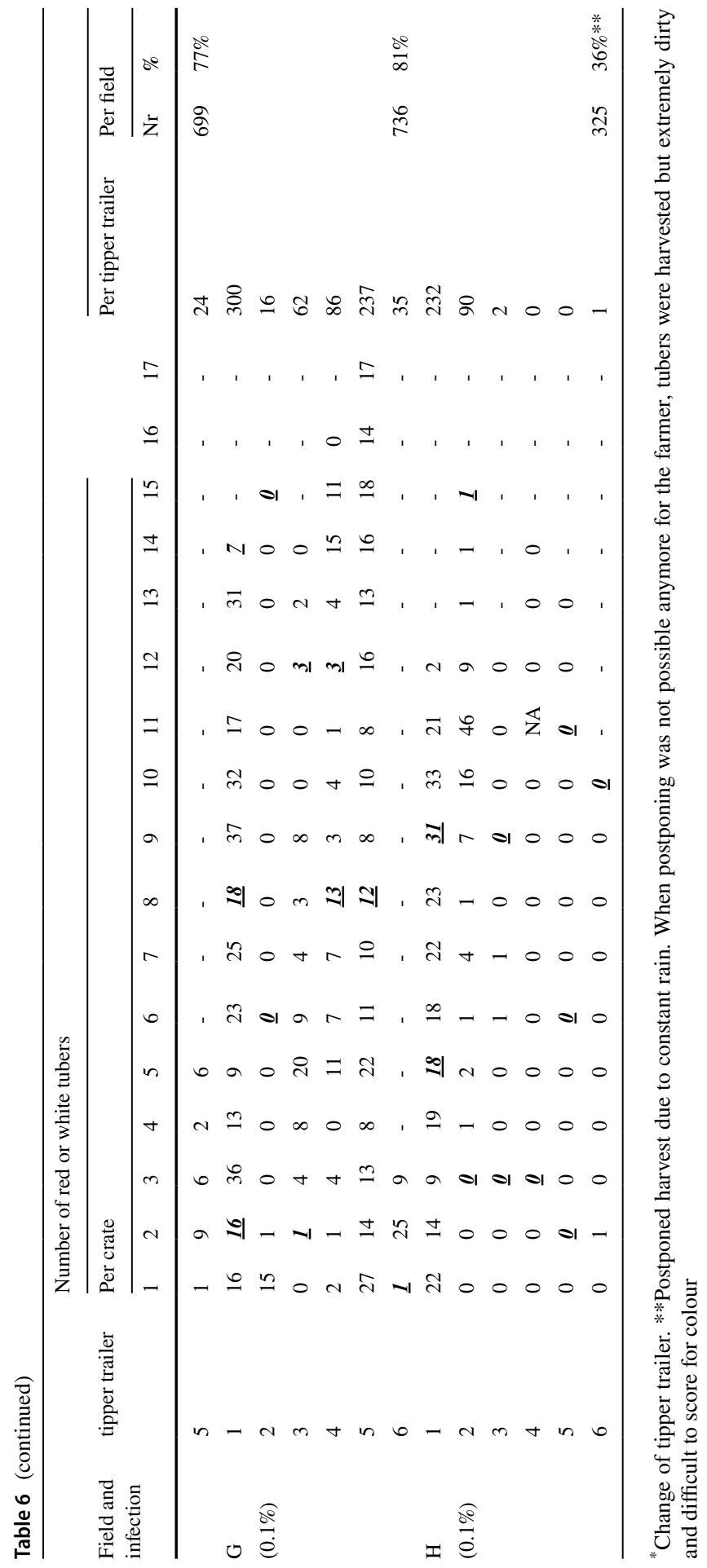


and spiralled outwards. The number of coloured 'infected' tubers, red tubers of cv. Bildtstar (2012) or white tubers of cv. Berber (2013), found per tipper trailer and per crate for each of the four different spatial distribution patterns, was determined during the sorting of the seed potatoes for tuber size. Bars of the same colour in Fig. 3 represent the crates originating from the same tipper trailer. From left to right (A to $\mathrm{D}$ and $\mathrm{E}$ to $\mathrm{H}$ ), we progress from a random distribution to the most aggregated distribution, consisting of one infestation focus in the centre of the field. We can clearly see that the randomly distributed potatoes provide a quite uniform distribution of 'infected' tubers throughout the different crates of a lot. When the spatial distribution is changing to a more aggregated distribution culminating into a single hot spot, a diminishing number of crates are infected, and the number of infected tubers per crates shows large differences. As the hot spot was situated in the middle of the tested field, we see that only those tipper trailers that traversed the artificial infestation were infected. We also observe that not all coloured skin tubers were retrieved. The percentage of recovery was on average $88.3 \%$ in 2012 and $65.3 \%$ in 2013. The lower percentage in 2013 was mainly due to bad weather, especially for field H. Harvest was postponed several times due to rainy weather and when the field was finally harvested the land was extremely wet and the tubers so 'dirty' from the heavy clay soil that recognition of the white tubers was severely hampered. Generally, not all tubers can be recovered during harvest as not all tubers will be harvested. According to Lumkes (1974) between 20,000 to 300,000 tubers per ha, 5-75\% of the yield, can be left in the field depending on cropping purpose and climatological circumstances. This is also reflected in the numbers of coloured skin 'infected " potatoes that can be retrieved from the test fields. In Table 6 bold italic data indicates the crates that ended up on top of the stacks and could contribute invisibly marked tubers to the 200-tuber sample for molecular analysis.

Table 7 Summary of the results of the invisibly marked 200-tuber sampling test per spatial distribution, including information on numbers of cluster per field, the number of positive and false-negative detections and the detection probability. 'Infection' rate in 2012 was $0.05 \%$ and in 2013 was $0.1 \%$

\begin{tabular}{lllllllll}
\hline Year & Field & Clustering & \multicolumn{2}{l}{ Number of } \\
\cline { 4 - 8 } & & & Clusters & Tubers & Reps & Positive & Negative & $\%$ Detection \\
\hline 2012 & A & Single tubers & 39 & 200 & 20 & 4 & 16 & 20 \\
2012 & B & Small clusters & 12 & 200 & 20 & 1 & 19 & 5 \\
2012 & C & Big clusters & 4 & 204 & 20 & 0 & 20 & 0 \\
2012 & D & One cluster & 1 & 200 & 20 & 1 & 19 & 5 \\
2013 & E & Single tubers & 130 & 200 & 20 & 8 & 12 & 40 \\
2013 & F & Small clusters & 12 & 200 & 20 & 3 & 17 & 15 \\
2013 & G & Big clusters & 4 & 200 & 20 & 5 & 15 & 25 \\
2013 & H & One cluster & 1 & 200 & 20 & 6 & 13 & 30 \\
\hline
\end{tabular}




\section{Tuber Sampling}

Twenty standard 200-tuber samples were collected from the top crates of each of the four different fields having a different spatial distribution pattern. Both front ends of each of the 16,000 collected tubers were cut to reveal the invisibly marked tubers. In 2012 , with a $0.05 \%$ incidence of invisibly marked tubers, only in 6 out of 80 tuber samples, could the infection be demonstrated by the presence of invisibly marked tubers. Each of the six samples where detection occurred contained only a single 'infected' tuber. In 2013, with a $0.10 \%$ incidence of invisibly marked tubers, in 22 out of the 80 tuber samples, invisibly marked tubers were present. Twenty of these were based on a single 'infected' tuber; and two samples contained two 'infected' tubers. The spatial distribution pattern of the invisible marked potatoes in the field had a marked effect on the detection in 2012. The random pattern provided the highest detection probability in the standard 200-tuber sample and the detection probability decreased with increasing clustering. In 2013 the random spatial distribution also resulted in the highest detection probability in the 200-tuber sample but did not have the same marked decline as in 2012 with the lower incidence $(0.05 \%)$. This was partly due to one top crate in field $\mathrm{H}$ from the infestation focus providing 5 detections. In Table 7, an overview is presented per year and per distribution pattern.

\section{Discussion}

It is generally accepted that blackleg is predominantly tuber-borne (Pérombelon 1974). There are no indications that the pathogen overwinters in soil and certainly will not survive in soil in a crop rotation of 3-8 years (Czajkowski et al. 2011; Toth et al. 2021). The analysis of the 26 naturally infested fields with more than 25 symptomatic plants for complete spatial randomness provided sound information that in 22 fields, diseased plants were randomly distributed at harvest, which indicates that the blackleg diseased plants came into the field as infected seed potatoes. It has been argued that during harvesting, sorting, grading and planting, the infected tubers of a seed lot, irrespective of the original distribution in the field, will be randomized over the seed lot explaining the non-aggregated distribution in most of the fields. However, the results of this paper show that an aggregated distribution pattern in the field is still maintained when the potatoes are graded (Fig. 3).

The four fields with an aggregated pattern of infested plants at the end of the growing season were checked for the development of their spatial pattern in time. Two of these fields, containing low numbers of infested plants early in the growing season, started with a random pattern that later changed into a clustered pattern. This indicates the appearance of secondary infestations occurring around the originally infected plants. The SRP may have been disseminated from blackleg-diseased to neighbouring plants via contact infections or via water (Boomsma et al. 2013; Kastelein et al. 2020). The other two fields, with a high number of infested plants early in the growing season, showed clustering from the start. It is possible that in 
these two severely infected seed lots, contact infections during planting may have contributed to the clustering of symptomatic plants.

Janse and Wenneker (2002) refer to an unpublished experiment in which artificial infections of Ralstonia solanacearum diseased tubers were created in plots of 1 ha. Tubers, either invisibly marked by a borehole or coloured skin, were added to the field. After harvesting, standard 200-tuber samples were collected from the top of the crates and analysed to substantiate the hypothesis of a random distribution of tubers in storage. Just like in the present research, Janse and Wenneker (2002) established different spatial distribution patterns in the field ranging from a random distribution up to a highly clustered distribution. The number of repetitions of the standard tuber sample was not specified, but the probability of finding marked tubers was reported to be consistent with a random distribution. This finding seems highly unlikely and indeed does not correlate with the results of this present research, which clearly provides a correlation between the distribution pattern in the field, the crates in storage and the 200-tuber samples. A drawback might have been the use of visibly marked tubers making it difficult to randomly collect 200 tubers as these tubers can be easily distinguished.

As the distribution of blackleg plants is predominantly random in the field, an extension of the surveyed area during the inspection will increase the probability of the detection proportionally, while the same increase of the surveyed area would result only in a marginal increase of detection when a more aggregated spatial distribution is present. The random spatial distribution of infected tubers in the field should result, after harvesting, in a uniform distribution of these tubers over all crates in storage. This is verified by the almost uniform distribution of the different coloured skin tubers, mechanically harvested, in the crates originating from the artificial random distribution in fields $\mathrm{A}$ and $\mathrm{E}$.

As the random distribution in the field causes an almost uniform distribution of 'infected' tubers over the crates, the positioning of the crates, e.g. the crates that will end up as top crates, will not cause an under- or over-estimation of the actual infestation in the field. Therefore, sampling of only the top crates will not produce any bias, unless conditions in the top crates are less favourable for survival of the pathogen during storage. The position of the crates may influence the relative humidity and therefore may affect survival (Chourasia and Goswami 2007).

Experiments with the invisibly marked, nail punctured tubers provided practical evidence on the theoretical impossibility to reliably detect a $0.05 \%$ or even a $0.1 \%$ symptomless infection at these infection incidence levels with the 200-tuber sampling method. At an incidence of $0.05 \%$, only 6 out of 80 tuber samples were detected and 22 out of 80 at an incidence of $0.1 \%$. One hundred thirty-two samples coming from the infested lots failed to detect the infestation. A 200-tuber sample is too small to ensure that at least one infected tuber is present in the sample. No improvement of laboratory methodology in the future, e.g. by using more than only the peel of the heel ends for detection, will make this method more reliable to detect SRP-infected tuber lots without first correcting the sample size. However, the required sample size of more than 4600 tubers (Fig. 1) to obtain a $90 \%$ reliability of detection at the $0.05 \%$ disease incidence level is unfeasible to accomplish, both in the number of tubers required for the test and the huge 
laboratory costs involved. Therefore, there is a limit in upgrading the size of the tuber sample and consequently a limit in improving the detection probability. The use of a laboratory test is only useful to test seed lots with an infection incidence of $1 \%$, such as may occur when during harvest and grading, the pathogen moves from soft-rotting to healthy tubers, either by direct contact or via bacterial slime left on harvesters or graders (Elphinstone and Perombelon 1986).

The detection probability not only depends on the disease incidence level, but also on the distribution of the infected tubers over the crates. All 6 out of 80 samples from the 'infected' lots at the $0.05 \%$ disease incidence level, and 20 of the 22 'infected' samples at the $0.1 \%$ disease incidence level were detected with a single 'infected' tuber. Only sample 9, field E and sample 3, field $\mathrm{H}$ contained 2 'infected' tubers. With complete randomness over the crates, over all tested distribution patterns, 7.4 detections should have occurred in 2012 and 14.5 in 2013. This fairly applies to the 2012 results, but in 2013 a larger number of detections occurred, mainly due to the detections occurring in field $\mathrm{H}$ with the highest aggregated distribution. In the 2013 samples, crate 9 from tipper trailer 1 also containing 30 'infected' coloured skin tubers, originating from the single big cluster from field $\mathrm{H}$ that ended up as a top crate and provided 5 positive tuber samples. However, as the results from the field survey indicate, the spatial distribution pattern is a random pattern, which excludes the extreme aberrations occurring with a highly aggregated distribution. It can be concluded that in practice, the maximum probability for detection of infected tubers is found.

The success of the NAK inspectors carrying out their inspection surveys, with more than $50 \%$ of the infected fields being detected, even after the farmers rogued the diseased plants they found during their own inspections, and considering that the inspectors survey only a small part of the field visually (5-10\%), is far better than the success rate of the 200-tuber sampling. An increase, e.g. doubling, of the currently inspected area per seed potato lot to $10-20 \%$ will have a significantly larger positive effect on the detection of infested seed potato lots than an equivalent increase in the number of tested tubers. As the extra costs will be only the extra time spent in surveying the plot - travel time and other actions being the same - cost will not double and an easy improvement will be realized.

The practice of rogueing (the removal of diseased plants) of seed potatoes by farmers is recommended by the seed certification procedures as a key component in maintaining the health status of the crop. However, according to Van der Wolf et al. (2021b), the efficacy of this method in controlling the spread of SRP bacteria is controversial since it does not always ensure sanitization of the entire crop (Bonde 1950; Pérombelon and Hyman 1992) as the tubers of the diseased plant will not be removed and still maintain an infection source. Boomsma et al. (2013) tested the efficacy of rogueing experimentally in the Netherlands without conclusive results. It is, therefore, expected that rogueing in controlling blackleg is only effective if the entire plant is physically removed, including the mother tuber as well as the progeny tubers, and measures are taken to prevent contact of diseased tissue with other plants in the field (De Boer et al. 2012). The practice of selection demands an intensive field inspection by the NAK to avoid the introduction of (severely) infected seed lots in the potato production chain. 


\section{Conclusions}

The following conclusions can be drawn from the data presented in this paper: There is a random distribution of blackleg diseased plants in the field. As a result, we can expect that the distribution of contaminated potatoes in storage over the crates will be quite uniform and no bias will occur when a standard 200-tuber sample is collected from the top crates. However, the data also provide proof that the standard 200-tuber sample is inadequate to detect an infestation with a high probability. Collecting more tubers to improve detection probabilities will only have a marginal effect on the reliability of the tuber sample. The actual number of tubers required to obtain a high detection probability - 90\% - requires so many tubers (4600) to be collected and tested that this will be an economically unfeasible solution. This indicates that improvement of laboratory methodology beyond the current state of the art hardly has a positive effect on the detection probabilities. You cannot detect something that is not present in your sample. Taking into account a random distribution of diseased plants in the field as demonstrated, a more effective strategy will be to survey a larger area during field inspections or to inspect with a higher frequency during the growing season.

Supplementary Information The online version contains supplementary material available at https://oi. org/10.1007/s11540-021-09529-6.

Acknowledgements This project was part of the research project 'Deltaplan Erwinia' financed by the Dutch seed potato industry and the Dutch Ministry of Economic Affairs. We are grateful to Harm Steenhuis, HZPC, for technical advice. We like to thank P. Haenen, Emmeloord, for providing the fields and technical advice. We also like to thank Ralph Post for technical assistance.

Open Access This article is licensed under a Creative Commons Attribution 4.0 International License, which permits use, sharing, adaptation, distribution and reproduction in any medium or format, as long as you give appropriate credit to the original author(s) and the source, provide a link to the Creative Commons licence, and indicate if changes were made. The images or other third party material in this article are included in the article's Creative Commons licence, unless indicated otherwise in a credit line to the material. If material is not included in the article's Creative Commons licence and your intended use is not permitted by statutory regulation or exceeds the permitted use, you will need to obtain permission directly from the copyright holder. To view a copy of this licence, visit http://creativecommons.org/licenses/by/4.0/.

\section{References}

Baddeley A, Rubak E, Turner R (2015) Spatial point patterns: methodology and applications with R. Chapman and Hall/CRC Press, London. ISBN 9781482210200, pp 810

Baddeley A, Turner R (2005) SpatStat: An R package for analyzing spatial point patterns. J Stat Softw 12(6): $1-42$

Bonde R (1950) Factors affecting potato blackleg and seed-piece decay. Bulletin. Maine Agricultural Experiment Station 482

Boomsma D, Velvis H, Kristelijn K, Van Tent Becking T, Kastelein P, Van der Zouwen, PS, Krijger MC, Förch MG, Van der Wolf JM, Czajkowski RL, Jafra S, Van den Bovenkamp G, de Haan E, Nunes Leite L (2013) Deltaplan Erwinia. Deel C - Pootaardappelen. Eindrapport van het onderzoek 2009 - 2012. Nederlands Aardappel Organisatie (NAO), Productschap Akkerbouw (PA). https://edepot.wur.nl/252391 
Chourasia MK, Goswami TK (2007) Steady state CFD modeling of airflow, heat transfer and moisture loss in a commercial potato cold store. Int J Refrig 30(4):672-689. https://doi.org/10.1016/j.ijref rig.2006.10.002

Czajkowski R, Perombelon MC, Van Veen JA, Van der Wolf JM (2011) Control of blackleg and tuber soft rot of potato caused by Pectobacterium and Dickeya species: a review. Plant Pathol 60(6):999-1013. https://doi.org/10.1111/j.1365-3059.2011.02470.x

Czajkowski R, Pérombelon MCM, Jafra S, Lojkowska E, Potrykus M, Van Der Wolf JM, Sledz W (2015) Detection, identification and differentiation of Pectobacterium and Dickeya species causing potato blackleg and tuber soft rot: a review. Ann Appl Biol 166(1):18-38. https://doi.org/10. 1111/aab.12166

De Boer SH, Li X, Ward LJ (2012) Pectobacterium spp. associated with bacterial stem rot syndrome of potato in Canada. Phytopathology 102:937-947

De Haan EG, Van Den Bovenkamp GW (2009) Test development in Erwinia at the NAK: BioPlex realtime PCR. Gewasbescherming 40(4):172-175

Elphinstone JG, Perombelon MCM (1986) Contamination of potatoes by Erwinia carotovora during grading. Plant Pathol 35:25-33. https://doi.org/10.1111/j.1365-3059.1986.tb01977.x

Janse JD, Wenneker M (2002) Possibilities of avoidance and control of bacterial plant diseases when using pathogen-tested (certified) or-treated planting material. Plant Pathol 51(5):523-536. https:// doi.org/10.1046/j.0032-0862.2002.00756.x

Kastelein P, Förch MG, Krijger MC, Van der Zouwen PS, Van den Berg W, Van der Wolf JM (2020) Systemic colonization of potato plants resulting from potato haulm inoculation with Dickeya solani or Pectobacterium parmentieri. Can J Plant Pathol. https://doi.org/10.1080/07060661.2020.1777465

Lumkes LM (1974) Potatoes as a weed. Causes, consequences and possibilities for control. Lelystad/ Wageningen: Research Station for Arable Farming/Proefstation voor de Akkerbouw

Ott RL, Longnecker M (2015) An introduction to statistical methods and data analysis. $7^{\text {th }}$ edition, ISBN: 9781305269477, pp 1296

Pérombelon MCM (1974) The role of the seed tuber in the contamination by Erwinia carotovora of potato crops in Scotland. Potato Res 17:187-199

Pérombelon MCM, Hyman LJ (1992) Control potato blackleg: production of healthy seed. Asp Appl Biol 33:77-84

Ripley BD (1976) The second-order analysis of stationary processes. J Appl Prob 13:255-266. https:// doi.org/10.2307/3212829

Toth IK, Barny MA, Brurberg MB, Condemine G, Czajkowski RL, Elphinstone JG, V. Helias, Steven B. Johnson, Lucy N. Moleleki, Minna Pirhonen, Simeon Rossmann, L. Tsror, JE van der Waals, J.M. van der Wolf, Frédérique van Gijsegem, Iris Yedidia (2021) Pectobacterium and Dickeya: environment to disease development. In: Van Gijsegem F., van der Wolf J.M., Toth I.K. (eds) Plant Diseases Caused by Dickeya and Pectobacterium Species. Springer, Cham. https://doi.org/10.1007/978-3-030-61459-1_3

Van der Wolf JM, Acuña I, De Boer SH, Brurberg MB, Cahill G, Charkowski AO, Coutinho T, Davey T, Dees MW, Degefu Y, Dupuis B, Elphinstone JG, Fan J, Esmaeil JF, Fazelisanagri E, Fleming T, Gerayeli N, Gorshkov V, Helias V, Le Hingrat Y, Johnson SB, Keiser A, Kellenberger I, Li X, Lojkowska E, Martin R, Perminow JI, PetrovaAgata Motyka-Pomagruk O, Rossmann S, Schaerer S, Sledz W, Toth IK, Tsror L, Van der Waals JE, De Werra P \& Yedidia I (2021c) Diseases caused by Pectobacterium and Dickeya species around the world. Plant diseases caused by Dickeya and Pectobacterium species. Springer, Cham. Pages 215-261. https://doi.org/10.1007/978-3-030-61459-1_7

Van der Wolf JM, De Boer SH, Czajkowski R, Cahill G, Van Gijsegem F, Davey T, Brice Dupuis, B, Ellicott J, Jafra S, Kooman M, Toth IK, Tsror L, Yedidia I, Van der Waals JE. (2021a) Management of diseases caused by Pectobacterium and Dickeya species. Plant diseases caused by Dickeya and Pectobacterium species. Springer, Cham. Pages 175-214. https://doi.org/10.1007/978-3-030-61459-1_6

Van der Wolf JM, Cahill G, Van Gijsegem F, Helias V, Humphris S, Xiang L, Lojkowska E, Pritchard L (2021b) Isolation, detection and characterization of Pectobacterium and Dickeya species. Plant diseases caused by Dickeya and Pectobacterium species. Springer, Cham. Pages 149-173. https://doi. org/10.1007/978-3-030-61459-1_5

Van Evert FK, Been TH, Booij JA, Kempenaar C, Kessel GJT, Molendijk LPG (2018) Akkerweb: A Platform for Precision Farming Data, Science, and Practice. Proceedings of the 14th International Conference on Precision Agriculture June 24 - June 27, 2018 Montreal, Quebec, Canada, pp 9

Publisher's Note Springer Nature remains neutral with regard to jurisdictional claims in published maps and institutional affiliations. 


\section{Authors and Affiliations}

Thomas H. Been ${ }^{1}\left[\right.$. Johanna E. Beniers ${ }^{1}$. Jan M. van der Wolf ${ }^{1}[$

Thomas H. Been

thomas.been@wur.nl

1 Wageningen University and Research, P.O. Box 16, 6700 AA Wageningen, the Netherlands 